\title{
Sentidos sobre Diversidade Sexual e o Trabalho de Psicólogas na Atenção Básica
}

\author{
Bárbara Anzolin ${ }^{1}$ \\ ${ }^{1}$ Universidade Paranaense, PR, Brasil.
}

\author{
Murilo dos Santos Moscheta ${ }^{2}$ \\ ${ }^{2}$ Universidade Estadual de Maringá, PR, Brasil.
}

\begin{abstract}
Resumo: Desde sua emergência como um discurso científico, a Psicologia produziu diferentes descrições da diversidade sexual e de gênero, incluindo desde as abordagens mais patologizantes e estigmatizantes até aquelas criticamente e politicamente engajadas. Pesquisas denunciam posturas profissionais preconceituosas e patologizantes, de profissionais que trabalham com o intuito de 'evitar' ou 'reverter a homossexualidade e/ou consideram-na uma "falha" ou "desvio". Considerando esse contexto, esta pesquisa buscou analisar os sentidos construídos sobre diversidade sexual e sobre o trabalho de psicólogas da Atenção Básica, participantes de uma oficina para qualificação profissional sobre o trabalho com a população LGBT. A pesquisa incluiu dois encontros com um grupo de 12 psicólogas em formato de oficina, realizados nos meses de fevereiro e março de 2016, nos quais foram trabalhadas noções contemporâneas sobre gênero e sexualidade, os recursos e os desafios para a atuação profissional. Os encontros foram gravados e transcritos naíntegra. A partir da oficina, construímos múltiplos sentidos sobre diversidade sexual e sobre o trabalho com a população LGBT. Os resultados estão apresentados em dois eixos: a) do tradicional ao contemporâneo: a polivocalidade e a polifonia sobre diversidade sexual; b) da dificuldade ao compromisso: a constante inovação das práticas psicológicas. A análise destaca a multiplicidade de sentidos que atravessam o campo da produção do cuidado em Psicologia e os diferentes entendimentos que reverberam em práticas ora conservadoras e normatizadoras, ora despatologizantes.
\end{abstract}

Palavras-chave: Diversidade Sexual, Psicologia, Construcionismo Social, Saúde Pública, Atenção Básica.

\section{Meanings about Sexual Diversity and Professional Practices of Psychologist in Primary Care}

\begin{abstract}
Since its emergence as a scientific discourse, psychology has produced different descriptions of sexual and gender diversity varying from pathologizing and stigmatizing approaches to critical and politically engaged ones. Researches denounces prejudiced professional positions of professionals who work to avoid or to reverse the homosexuality or consider this like a 'failure' or 'detour'. In this context, this research analyze meanings about sexual diversity and psychological practice constructed by primary care services, psychologist who have participated in a workshop for professional qualification in LGBT issues. The research included two group meetings with 12 psychologists conducted in February and March of 2016, in which contemporary notions of gender and sexuality were discussed as well as resources and challenges in professional practices. The meetings were recorded and transcribed. From the workshop we have multiple meanings about sexual diversity and about the work with the LGBT population. The results are presents in two axes: a) From the traditional to contemporary: polyvocality and polyphony about sexual diversity; b) From difficulty to commitment: the constant innovation of psychological practices. The analysis highlights the multiplicity of meanings in the field of the production of care in psychology and the different understandings reverberate in practices sometimes conservatives and normatized, sometimes depathologizing.
\end{abstract}

Keywords: Sexual Diversity, Psychology, Social Constructionism, Public Health, Primary Care. 


\title{
Sentidos sobre la Diversidad Sexual y el Trabajo de Psicólogas en la Atención Básica
}

\begin{abstract}
Resumen: Desde su emergencia como un discurso científico, la psicología ha producido distintas descripciones de la diversidad sexual y la de género, incluyendo desde los enfoques que patologizan y estigmatizan hasta aquellas críticamente y políticamente comprometidas. Las investigaciones denuncian posturas profesionales preconcebidas y patologizantes, de profesionales que trabajan con el propósito de 'evitar' o 'reveritr' la homosexualidade y/o la consideran una 'falla' o 'desvío'. En consideración a ese contexto, esta investigación buscó analizar los sentidos construidos sobre diversidad sexual y sobre el trabajo de psicólogas de la atención básica, participantes de un taller de cualificación profesional sobre el trabajo con la población LGBT. La búsqueda incluyó dos encuentros con un grupo de 12 psicólogas en forma de taller, en los meses de febrero y marzo de 2016, en los cuales fueron trabajadas nociones contemporáneas sobre género y sexualidad, los recursos y los desafíos para la actuación profesional. A partir de los encuentros realizados, hemos construido múltiplos sentidos sobre la diversidad sexual y sobre el trabajo con la populación LGBT. Los encuentros fueron grabados y transcritos en su totalidad. A partir del taller, construimos múltiples sentidos sobre diversidad sexual y sobre el trabajo con la población LGBT. Los resultados se apresentan en dos ejes: a) de lo tradicional al contemporáneo: la polivocalidad y la polifonía sobre diversidad sexual; b) de la dificuldad al compromiso: la constante innovación de la prácticas psicológicas. El análisis destaca la multiplicidad de sentidos que cruzan el campo de la producción del cuidado en psicología y los diferentes entendimientos reverberan en prácticas ora conservadoras y normatizadoras, ora despatologizantes.
\end{abstract}

Palabras clave: Diversidad Sexual, Psicología, Construccionismo Social, Salud Pública, Atención Básica.

\section{Introdução}

Esse artigo analisa os sentidos construídos sobre diversidade sexual e sua relação com o trabalho com a população LGBT de psicólogas que atuam na Atenção Básica de Maringá/PR. Adotamos o uso do termo diversidade sexual para nos referirmos às possibilidades de orientação sexual e expressões de gênero diferentes da norma heterossexual, vivências que não se adequam à inteligibilidade cultural construída para homens e mulheres a partir do binarismo de gênero, e que são comumente representadas na sigla LGBT - lésbicas, gays, bissexuais, travestis e transexuais (Toneli, 2008).

Utilizamos o termo "trans" para nos referirmos às pessoas travestis, transexuais e demais vivências que divergem da norma binária de gênero (feminino e masculino), e entendemos o termo cisgênero como aquele que descreve corpos cuja identificação com o gênero mantém congruência com os órgãos genitais (mulheres com vulva e homens com pênis).
O material discutido aqui é resultado de uma pesquisa-intervenção desenvolvida em 2017, fundamentada teórica e tecnicamente no construcionismo social. Iniciamos este texto com a apresentação de algumas considerações acerca da relação entre Psicologia e as sexualidades. Em seguida, discutimos a inserção da Psicologia nas Políticas Públicas, mais especificamente nas políticas de saúde, e as práticas dentro do Sistema Único de Saúde (SUS) e em relação a Política Nacional de Atenção Integral à Saúde de LGBT (Brasil, 2013).

\section{A relação da Psicologia com as sexualidades}

Entender a sexualidade e a diversidade sexual como construções sociais, significa pensar que são produzidas e controladas dentro de um campo tensional de práticas e discursos múltiplos, contingentes aos momentos históricos e organizados a partir de diferentes campos de inteligibilidade (Louro, 2008). 
No campo científico, destacamos o discurso biomédico, o psicológico e o jurídico, e no campo não científico destacamos os religiosos e também o dos movimentos sociais de militância. Estes discursos produzem descrições e leituras sobre a sexualidade em múltiplas direções, mais ou menos convergentes, mas que cooperam para a inscrição das práticas relacionadas ao corpo e aos prazeres em um registro normativo. Ou seja, constroem a noção de sexualidades normais e anormais (Foucault, 1987/2015).

O estudo da história dos discursos científicos sobre a sexualidade, que encontra em Foucault (1987/2015) um aporte fundamental, demonstra que as práticas sexuais entre pessoas de mesmo gênero e as vivências de pessoas trans já foram descritas como pecado, crime, desvio e patologia (Vecchiatti, 2012; Teixeira, 2011b; Moscheta, 2011). Para Foucault (1987/2015), o discurso médico científico do século XIX possibilitou o deslocamento do conjunto de saberes normativos sobre as práticas sexuais, migrando sua ênfase do campo religioso e jurídico (mas sem silenciá-los) para o campo médico-psiquiátrico (Foucault, 1987/2015).

No final do século XIX, quando a Psicologia foi concebida como ciência, as práticas sexuais entre pessoas do mesmo gênero já eram vistas como patologia pela ciência médica (Teixeira, 2011a). Contudo, a Psicologia participou ativamente da patologização das sexualidades dissidentes, oferecendo um aporte fundamental por meio da produção de conhecimentos, imposição de diagnósticos e proposição de tratamentos. Associada aos entendimentos moralistas da época, assumiu a matriz heterossexual como essencial, natural e normal, e fundamentou variadas propostas terapêuticas, no intuito de reorientar a sexualidade de pessoas da homossexualidade para a heterossexualidade (Gimenes \& Vieira, 2012).

O discurso patologizante da ciência produziu identidades encapsuladas e restritas ao denominador de seu "desvio sexual". Anos depois, a afirmação dessa identidade possibilitou a organização de um movimento de resistência, quando pessoas LGBT puderam se identificar enquanto grupo, e, deste lugar, agenciar forças contrárias às opressões até então vividas. A partir da década de 1970, os movimentos militantes LGBT passam a afirmar a diversidade sexual como possibilidades legítimas de existência humana (Barreto, 2016; Borges, 2014; Bessa, 2014; Brasil 2013). Em decorrên- cia destas lutas, a homossexualidade foi retirada do rol de transtornos do Manual Diagnóstico de Transtornos Mentais (DSM) (American Psychiatry Association [APA], 2014) - em 1973, e do Código Internacional de Doenças - CID - em 1990 (Organização Mundial da Saúde [OMS], 1998). Em 2018 também foi noticiada a retirada da vivência trans do rol de transtornos mentais da $11^{a}$ versão do CID, a ser apresentada oficialmente em maio de 2019 (OMS, 2018).

Neste contexto, a Psicologia vem sendo influenciada, questionada pelos movimentos sociais e, ao menos em parte, transformada. Em contraposição à patologização, a partir da década de 1990, ganharam força leituras e posicionamentos profissionais antidiscriminatórios, como aqueles consolidados pela Resolução 001/99 (Resolução CFP n. 1, 1999), que estabelece normas para a atuação de profissionais de Psicologia junto às pessoas LGBT; pela nota técnica sobre o processo transexualizador (CPF, 2013), que instrui o papel desse profissional durante o processo; e pela Resolução no 01/2018 (Resolução CFP n. 1, 2018), que impede o uso de técnicas psicológicas para manter ou reforçar a discriminação e preconceito contra pessoas LGBT.

Os documentos publicados refletem a necessidade de se regular um campo de teorias e práticas muito heterogêneo e frequentemente em disputa. Muitos profissionais, e até mesmo grupos organizados de profissionais, desafiam as resoluções do Conselho ao reivindicarem o direito a proposição de práticas de "tratamento" da homossexualidade, como o Corpo de Psicólogos/as e Psiquiatras Cristãos (CPPC), por exemplo (Sposito, 2015; Moscheta, 2011) a despeito das largas evidências científicas da ineficácia desse tipo de proposição terapêutica e em desconsideração aos debates éticos que condenam tais práticas. De modo semelhante, ainda perduram nos currículos de formação em Psicologia tendências de ensino que reproduzem um entendimento essencialista e normativo da sexualidade e pesquisas apontam a prevalência de visões preconceituosas e patologizantes de profissionais e estudantes de Psicologia e de outras áreas, com relação à diversidade sexual (Dinis, 2012; Moita, 2006; Rios \& Nascimento, 2007; Díaz, 2012; Sposito, 2015; Nardi, Machado, Machado, \& Zenevich, 2013). Luis Rios e Ítala Nascimento (2007) buscaram conhecer as visões sobre diversidade sexual de psicólogos de Recife atuando principalmente sobre enfoque humanista e psicana- 
lista. Concluíram que os profissionais entretinham visões variadas sobre a homossexualidade. Contudo, poucos profissionais se reconheceram capazes de atuar contra o preconceito.

No mesmo sentido, a pesquisa de Detoni Marques, Soares, e Nardi (2011) com pessoas não exclusivamente heterossexuais que tinham experiências de psicoterapia, aponta que alguns dos terapeutas estabeleciam relação entre a orientação sexual e abuso sofrido na infância, ou falhas nas figuras materna/ paterna. Concluem que "a construção do corpo homossexual para alguns(algumas) psicólogos(as) parece ser inteligivel apenas na ordem da falha ou do trauma" (Detoni et al., 2011, p. 287).

A partir de entrevistas realizadas com homens gays, que fizeram ou fazem psicoterapia, Bessa (2014) descreve situações nas quais em que os participantes não se sentiram confortáveis com a reação e o trabalho profissional, por sentirem que a psicóloga 'estimulava a ser heterossexual' ou mesmo por não terem gostado da reação profissional quando relataram a homossexualidade.

Reconhecemos que há muitas e muitos profissionais bem-intencionadas e intencionados que, embora busquem realizar um trabalho ético e "sem preconceitos", acionam práticas e teorias que reproduzem a lógica binária, essencializante e o olhar para as sexualidades marginalizadas, ainda, como inferior. A possibilidade de a prática psicológica ser reprodutora de exclusão social, muitas vezes, passa despercebida (Bessa, 2014).

Destacamos que a discriminação não se limita aos consultórios psicológicos e outros espaços privados, ocorre também nos serviços públicos, inclusive na saúde. Ainda que tenhamos os já citados materiais do Conselho de Psicologia disponíveis, sobre a temática, e a Política Nacional de Atenção Integral à Saúde da população LGBT (Brasil, 2013), nem todas as psicólogas e psicólogos buscam e acessam esses materiais. Muitas vezes, os materiais produzidos pelo Ministério da Saúde e outros órgãos não chegam até elas e eles nos serviços de saúde.

Gabriela Andrea Díaz (2012), que pesquisou sobre as concepções de sexualidades de psicólogas e psicólogos que trabalham em Unidade Básica de Saúde (UBS) de Florianópolis/SC, aponta que as e os participantes não receberam capacitação, formação, discussão, materiais ou qualquer atividade sobre a temática LGBT e suas questões de saúde, por parte do poder público. Não se fala sobre o assunto profissionalmente, e, na maioria das vezes, os atendimentos nas unidades são voltados "essencialmente para a família heterossexual, com consequente exclusão dos que não fazem parte dela" (Díaz, 2012, p. 9). Isso denuncia a distância entre as propostas da política de saúde LGBT e as práticas profissionais na saúde, configurando um cenário distante daquele almejado pelo Conselho de Psicologia e pelo SUS, em seus princípios.

\section{Saúde, Estado e Psicologia}

Ao inserir-se nas políticas públicas a partir da década de 1970, a Psicologia foi desafiada a trabalhar na dimensão da garantia de direitos e com uma lógica de atuação mais preventiva e de promoção de saúde (Macedo \& Dimenstein, 2012). Criou-se um contexto no qual profissionais de Psicologia precisavam pautar a sua prática em princípios do campo das políticas de saúde e não apenas da Psicologia.

Tendo como princípios doutrinários a Universalidade, Integralidade e Equidade, as políticas do Sistema Único de Saúde (SUS) estão embasadas na visão ampliada de saúde e nos Determinantes Sociais de Saúde (DSS). Esta visão considera a saúde como um processo multideterminado por fatores biopsicosociais, e trabalha com um conjunto de ações de promoção e proteção da saúde, prevenção de agravos, diagnóstico, tratamento, reabilitação, redução de danos e manutenção da saúde, no âmbito individual e coletivo (Brasil, 1990; Souza, Silva \& Silva, 2013).

Dentre as políticas do SUS, três são de especial importância para a discussão que empreendemos aqui: a) Política Nacional de Atenção Básica (PNAB) (Brasil, 2012; Portaria n. 2.436, 2017); b) Política Nacional de Atenção Integral à Saúde de Lésbicas, Gays, Bissexuais, Travestis e Transexuais (Brasil, 2013); e c) as Políticas de Formação e Desenvolvimento para o SUS (Brasil, 2003).

Destacamos a PNAB, pelo contexto de realização da pesquisa, que teve como participantes psicólogas que atuam na Atenção Básica. Para além dos princípios doutrinários do SUS, a PNAB propõe os princípios da acessibilidade, do vínculo, da continuidade do cuidado, da responsabilização e da humanização, configurando uma atenção à saúde centrada nas pessoas e nos DSS. A Política de Saúde LGBT pauta-se na compreensão dos DSS para propor ações 
de enfrentamento à lgbtfobia e defesa do cuidado em saúde com equidade.

As Políticas de Formação e Desenvolvimento para o SUS, por sua vez, contemplam a formação de Recursos Humanos da área da saúde, proposta na Constituição Federal (1988) - Artigo 200 -, e na Lei Orgânica da Saúde (Lei n. 8.080, 1990) - Artigo 6º ${ }^{\circ}$ Uma das diretrizes da Política de Saúde LGBT, que dialoga com a formação continuada no SUS, é a inclusão da "temática da orientação sexual e identidade de gênero de lésbicas, gays, bissexuais, travestis e transexuais nos processos de educação permanente desenvolvidos pelo SUS, incluindo os trabalhadores da saúde, os integrantes dos Conselhos de Saúde e as lideranças sociais" (Brasil, 2013, p. 23). É este contexto que nos permite pensar a qualificação da atenção à saúde da população LGBT.

Considerando a inserção da Psicologia nas Políticas Públicas e o modo como a Psicologia foi modificando o seu modo de abordar a sexualidade, nos propusemos a analisar os sentidos construídos sobre diversidade sexual e sobre o trabalho com pessoas LGBT de psicólogas que atuam na Atenção Básica de Maringá/PR.

\section{Trajetória metodológica}

A pesquisa realizada utilizou como principal estratégia de produção de dados uma oficina para psicólogas que trabalham na Atenção Básica (AB) em Maringá/PR. O projeto de pesquisa foi submetido a avaliação e aprovado pelo Comitê Permanente de Ética em Pesquisa com Seres Humanos (COPEP) conforme parecer número 1.406.388.

A oficina realizada contemplou 2 encontros de 3 horas e meia cada um, e ofereceu 12 vagas para participantes. A coordenação de Saúde Mental do município enviou, por e-mail, um convite às psicólogas e psicólogos que atuam na $\mathrm{AB}$ (Equipes de Núcleo de Apoio à Saúde da Família - NASF - e UBS). Ressaltamos que o grupo de psicólogas que participou da oficina foi composto pelas primeiras doze pessoas que se inscreveram, das quarenta e duas convidadas, que trabalham como psicólogas/os na Atenção Básica do município. No intuito de preservar o sigilo de suas identidades, seus nomes foram substituídos por cores. Consideramos as inscrições das participantes um fator relevante, na medida que nos permite compreendê-las como interessadas no assunto, pois rapidamente se ofereceram para parti- cipar. Esse interesse e abertura foram confirmados por elas durante os encontros.

As participantes tinham de 1 a 25 anos de formação em Psicologia, e de 6 meses a 19 anos de experiência de trabalho concursadas no campo da saúde pública. Quatro psicólogas estavam trabalhando em equipes NASF, e oito em UBS, no período em que foi realizada a oficina. Todas são mulheres cisgênero e as que comentaram sobre seus relacionamentos pessoais, ao longo da oficina, fizeram referência ao casamento heterossexual, monogâmico e algumas têm filhas e filhos. O Quadro 1 resume a composição do grupo de participantes.

Quadro 1

Características do grupo participante.

\begin{tabular}{lccc}
\hline $\begin{array}{l}\text { Tempo de } \\
\text { formação }\end{array}$ & $\begin{array}{c}\text { Tempo de } \\
\text { trabalho } \\
\text { prefeitura }\end{array}$ & $\begin{array}{c}\text { Equipe de } \\
\text { trabalho }\end{array}$ & $\begin{array}{c}\text { Número de } \\
\text { encontros que } \\
\text { participou }\end{array}$ \\
\hline 15 anos & 15,0 anos & UBS & 1 \\
1 ano & 6,0 meses & NASF & 2 \\
7 anos & 5,5 anos & NASF & 2 \\
8 anos & 2,0 anos & NASF & 2 \\
14 anos & 3,5 anos & UBS & 2 \\
11 anos & 2,0 anos & UBS & 1 \\
23 anos & 19,0 anos & UBS & 1 \\
6 anos & 5,0 anos & NASF & 2 \\
9 anos & 4,0 anos & UBS & 1 \\
25 anos & 14,0 anos & UBS & 2 \\
14 anos & 6,0 anos & UBS & 2 \\
Não & 5,5 anos & UBS & 2 \\
respondeu & & & \\
\hline
\end{tabular}

NASF: Núcleo de Apoio à Saúde da Família; UBS: Unidade Básica de Saúde.

A maioria (11 participantes) relatou já ter falado sobre $\mathrm{o}$ assunto nas unidades que trabalham, com as equipes e/ou nas reuniões de saúde mental do município (fruto de palestras, discussão de caso, eventos). Apenas uma delas referiu ser a oficina um primeiro contato. No que tange ao conhecimento prévio sobre a política e questões de saúde LGBT, das oito participantes que compareceram ao segundo encontro, cinco já tinham ouvido falar da existência de uma 
política de saúde específica sobre a população LGBT, mas apenas uma delas havia lido.

A escolha pelo método de oficina se deu pelo potencial de sensibilização das pessoas para a temática e de negociação de sentidos, ao permitir a visibilidade de diferentes versões e argumentos sobre diversidade sexual, por parte de cada participante e de suas vivências. É um método que, "ao mesmo tempo em que geramos material para análises, criamos um espaço de trocas simbólicas que potencializam a discussão em grupo em relação à temática proposta, gerando conflitos construtivos com vistas ao engajamento político de transformação" (Spink, Menegon \& Medrado, 2014, p. 33).

Os encontros foram planejados para produzir sentidos sobre as práticas profissionais que desenvolvem e ao mesmo tempo favorecer a problematização dessas práticas, de modo a contribuir para qualificação profissional. Por "produção de sentidos", entendemos um "empreendimento coletivo mais precisamente interativo, por meio do qual as pessoas, na dinâmica das relações sociais, historicamente datadas e culturalmente localizadas, constroem os termos a partir dos quais compreendem e lidam com as situações e fenômenos à sua volta" (Spink, 2010, p. 34). É no diálogo que eles são construídos e negociados, no exercício de "falar, responder, explicar-se, argumentar, defender-se etc." (Guanaes \& Japur, 2008, p. 118).

$\mathrm{Na}$ oficina de capacitação, incluímos momentos em que foram apresentadas: noções contemporâneas sobre gênero e sexualidade; DSS relevantes para a discussão da saúde de pessoas LGBT; alguns dados estatísticos e considerações sobre violências contra pessoas LGBT; recursos e desafios nos atendimentos; e foram discutidos alguns pontos da Política Nacional de Saúde Integral de LGBT, como o histórico e seus objetivos. As atividades tiveram o propósito específico de promover trocas dialógicas que permitissem a visibilidade, problematização, construção e deslocamento de sentidos sobre diversidade sexual.

A estrutura contemplou acolhimento, aquecimentos, atividades específicas e avaliação, que foram pensadas com o propósito de: proporcionar um ambiente em que as pessoas se sentissem à vontade para falar sobre a temática; colocá-las para conversar; fazer exercícios preparatórios que mobilizassem o grupo para o foco da nossa proposta; e realizar ati- vidade disparadora de diálogos. Os diálogos versaram sobre: a) sentidos sobre diversidade sexual; b) recursos e desafios no atendimento à população LGBT; e c) possibilidades de atuação com LGBT a partir de casos, em diálogo com a Política de Saúde LGBT e outros documentos do Ministério da Saúde e do Conselho Federal de Psicologia.

Os encontros foram realizados em sala disponibilizada pela Secretaria de Saúde. No primeiro encontro participaram as doze inscritas e, no segundo, retornaram oito. Para analisar os sentidos produzidos nos diálogos, os encontros foram gravados em áudio e transcritos integralmente.

Empreendemos a análise das práticas discursivas, como proposto por Spink e Medrado (2013). As práticas discursivas podem ser entendidas como a linguagem em ação, ou seja, o modo como as pessoas produzem sentidos e como esses sentidos implicam em suas relações cotidianas, em suas práticas. Elas produzem sentidos, ressignificação, entendimentos coletivos que consistem em narrativas, comentários, argumentações, conversas e "os repertórios utilizados nessas produções discursivas" (Spink \& Medrado, 2013, p. 23).

Os repertórios linguísticos "são os termos, os conceitos, os lugares comuns e figuras de linguagem que demarcam o rol de possibilidades de construções de sentidos" (Spink, 2010, p. 32), ou seja, “o sentido decorre do uso que fazemos dos repertórios interpretativos de que dispomos" (Spink \& Medrado, 2013, p. 27). A partir da epistemologia construcionista social, os sentidos construídos sobre algo são importantes, pois implicam no modo como podemos nos relacionar com este algo. Isto é, o modo como as ações de cuidado em saúde para pessoas LGBT podem ser desenvolvidas por profissionais de Psicologia da $\mathrm{AB}$ está indissociavelmente relacionado aos sentidos que estas profissionais constroem sobre a diversidade sexual.

Para analisarmos os sentidos, primeiramente, identificamos os termos que compõem o repertório linguístico dos diálogos e identificamos temas a partir do agrupamento dos repertórios. Em seguida, criamos dois eixos de análise: a) do tradicional ao contemporâneo: a polivocalidade e a polifonia sobre diversidade sexual; e b) da dificuldade ao compromisso: a constante inovação das práticas psicológicas. 
Em consonância com os pressupostos construcionistas sociais, entendemos que o que apresentamos não é um registro de uma suposta realidade estática, mas uma busca de apreensão de um movimento, composto por forças e tendências que se agenciam nesse momento com a produção de determinados efeitos. Para o diálogo no texto, demarcamos os sentidos construídos em negrito e os repertórios linguísticos (termos utilizados na oficina) que nos permitiram construí-los em itálico e entre aspas.

\section{Resultados}

\section{A polivocalidade e a polifonia sobre diversidade sexual}

Nas oficinas realizadas, a diversidade sexual foi descrita por meio de palavras como "confuso", "dificil", "muita informação", "muito diferente", "tudo do mesmo balaio", "tudo gay", "complexo" e "desafio". Ou seja, algo obscuro, de difícil entendimento, como se fosse um enigma, algo ininteligível, distante e que necessita ser decifrado. A sexualidade também foi pensada como um tabu, algo íntimo na vida das pessoas, nas palavras das participantes: "algo ainda muito intimo"; "a sociedade teme muitos tabus".

Em alguns momentos da oficina conversamos sobre situações de atendimento a usuários(as) LGBT, alguns realizados pelas profissionais participantes, outros fictícios. Ao conversarmos sobre o caso fictício de Mariana, uma adolescente cujos pais souberam que foi vista beijando outra menina, as participantes comentam:

Rosa: A gente discutiu bastante a questão da adolescência, será que não é uma fase natural que ela está passando de curiosidade... de descobertas?

Laranja: Facilitar o diálogo entre eles, por que tem o outro filho também, de 17 anos, então, se aparentemente a criança está com algum problema mais sério, e o outro como é que foi? (Encontro 2).

Nestes comentários notamos os sentidos sobre as vivências sexuais e de gênero não normativas como uma fase transitória, "de curiosidade" e como um "problema mais sério".
Notamos também, em outros momentos da oficina, o entendimento sobre a homossexualidade como inferior à heterossexualidade, algo indesejado.

Verde: [...] a gente, enquanto pais, nós estamos à mercê, a qualquer momento, nosso filho vai chegar para a gente e vai falar "sou gay" [...] e eles não vão deixar de ser nossos filhos por isso. Óbvio que ninguém engravida e pensa "nossa, eu queria tanto que meu filho quando crescesse fosse homossexual" [...] (Encontro 1).

Os comportamentos dissidentes dos padrões socialmente construídos de gênero foram descritos como inconvenientes, o que nos permitiu construir o sentido de visibilidade que incomoda:

Verde: Eu me sinto tão desconfortável, por exemplo, sei lá, com um homossexual muito gritante, como talvez com um homem muito gritante, que fica do meu lado, dando em cima de mim descaradamente. Não é por ser homossexual, né? É pela forma como se relaciona comigo, acho que isso não tem a ver com a homossexualidade.

Participante não identificada: Eu acho que isso não tem a ver com a sexualidade.

Verde: Exatamente (Encontro 1).

Durante as conversas, também percebemos a associação de pessoas LGBT com uma condição de sofrimento. As participantes fazem referência àquilo que poderíamos classificar em três modalidades: a) sofrimento que elas relacionam ao social; b) sofrimento de mães e pais de LGBT; e c) sofrimento relacionado à auto aceitação/conflito pessoal:

Vermelha: [...] porque, era para ser uma conversa para realmente os pais caírem em si do real sofrimento do menino, porque já foi colocado várias situações em que ele já tentou se mutilar para resolver o problema. [...] entendendo que ele não tinha outro espacinho na cabeça para aprender, o conflito é diário e constante [...] (Encontro 2).

As participantes se referem à população LGBT como pessoas vítimas de violência, preconceito e discriminação, em função de sua sexualidade, portanto, 
pessoas mais vulneráveis. Considerando esse sofrimento de LGBT relacionado ao social, por extensão, mães e pais também sofreriam, seja por testemunharem a "dor" de filhas e filhos, seja pelo esfacelamento das próprias expectativas.

Laranja: Independente de que seja natural [...] na sociedade que ela vai viver, ela vai ter que escolher se vai assumir isso, se não, [...] e como vai ser essa violência contra ela? Esse preconceito...

Verde: e aí a gente vê o tanto que isso vem com sofrimento, essa coisa de "não sou eu que escolhi”, realmente, né? (Encontro 1).

Além da condição de sofrimento, aqui notamos também a diversidade sexual como uma condição individual, algo natural, desde o nascimento, uma essência. Por ser natural, é atribuída apenas à pessoa a responsabilidade por suas vivências.

Em outros momentos a diversidade sexual foi descrita por meio de palavras como "maravilhosa", "maturidade", "evolução cultural", "coisa boa", "vida", "desejo" e "jeito de ser", o que nos permitiu construir os sentidos de Possibilidades e Evolução Cultural.
Outros comentários nos permitiram construir os sentidos de Peculiaridade - algo singular nas vivências de LGBT, associado à noção de subjetividade, como o de Lilás: "palavra diversidade, que lembra diferente, como se as pessoas fossem classificadas, e aí eu pensei que cada um tem um jeito de ser também, né? É classificado como gay, lésbica, homem, mulher, mas cada um tem a sua subjetividade" (Encontro 1).

Uma das atividades propostas convidava as participantes a pensarem possibilidades de ações, nos serviços onde elas trabalham. Nesta atividade, elas afirmam a necessidade de falar sobre o assunto, serem 'multiplicadoras' das informações, falar sobre leis e políticas, defendendo a população LGBT como Sujeitos de Direitos.

Um outro sentido que construímos foi o de Pessoas Afetuosas, a partir de comentários sobre duas fotos, uma com um casal de mulheres e outra com um casal de homens: "Marrom: [...] é uma imagem bonita. São duas pessoas que se amam, né? Independente do sexo delas, as pessoas imaginam 'tem que ser homem e mulher', não, são duas pessoas que se amam" (Encontro 1).

Apresentamos no Quadro 2 todos os sentidos deste eixo e os termos que contribuíram para sua construção:

Quadro 2

Do tradicional ao contemporâneo: a polivocalidade e a polifonia sobre diversidade sexual.

\begin{tabular}{|c|c|}
\hline Sentidos & Termos que contribuíram para a construção dos sentidos \\
\hline Enigma & Indefinido/ininteligível, estranho, distante, desconhecido, difícil, desafio \\
\hline Tabu & Tabu, íntimo, rótulo \\
\hline Condição individual & $\begin{array}{l}\text { Condição individual, condição, algo interno, natural desde o nascimento, normal, } \\
\text { natural, tranquilo, faz parte }\end{array}$ \\
\hline Condição de sofrimento & $\begin{array}{l}\text { Sofrimento, bullying, sofrimento dos pais, reprimido, incomum, escondido, futuro } \\
\text { menos promissor }\end{array}$ \\
\hline Surpresa & Surpresa, inesperado, quebra expectativas \\
\hline Vulnerabilidade & Vulnerabilidade, grupo de risco, DST \\
\hline Indesejado & Algo ruim, indesejado \\
\hline Visibilidade que incomoda & Visibilidade que incomoda/invisível \\
\hline Fase transitória & Transitório, fase de descoberta, não legítimo \\
\hline Sujeitos de direitos & Sujeitos de direitos, integralidade \\
\hline Possibilidades & Possibilidade de vida, desejo, jeito de ser, possibilidade legítima \\
\hline Evolução cultural & Coisa boa, maravilhosa, maturidade, evolução cultural \\
\hline Peculiaridade & Singularidade, peculiaridade \\
\hline Pessoas afetuosas & Afeto, amor \\
\hline
\end{tabular}

DST: doença sexualmente transmissível. 


\section{Da dificuldade ao compromisso: a constante inovação das práticas psicológicas}

Nesta categoria, apresentamos alguns sentidos que construímos com relação à prática profissional das psicólogas com a população LGBT. Os sentidos foram construídos a partir dos diálogos sobre como elas trabalham, ao que recorrem para atender, como articulam seus recursos e lidam com as dificuldades.

Um dos casos mais comentados na oficina, foi o caso de Arco-íris, uma criança de 7 anos atendida por duas das profissionais presentes na oficina, cuja mãe inicialmente relatou que o filho tinha dificuldade de aprendizagem. Nos atendimentos, Vermelha identificou que a criança estava sofrendo porque ela gostava de coisas (brinquedos, roupas, brincadeiras) ditas de menina, e era impedida de usá-las por ser reconhecida como um menino: "Vermelha:... A Azul participou dessa discussão, a Branca participou e, lógico, percebendo a minha limitação com relação ao assunto, que era novo, e falando de sexualidade em si, é importante a gente buscar mais informação" (Encontro 2).

Este trecho nos ajuda a apresentar os sentidos sobre a prática profissional com a população LGBT como novidade, delicado e desconcertante. As profissionais se posicionam como "limitadas" com relação à temática. Ao se depararem com a novidade, elas se mobilizam para dar conta desta novidade, discutindo o caso em conjunto e acionando a rede:
Azul: Será que encaminhar para o CAPS infantil é interessante? Entendendo que o CAPS é um lugar para atender crianças com algum transtorno, e a gente não queria, na verdade, enquadrá-lo nessa de transtorno. Porque, na verdade, ele não está doente, a questão dele é que ele não pode manifestar tudo o que ele sente porque as pessoas ao redor dele não aceitam (Encontro 2).

Estes, e outros posicionamentos semelhantes, nos permitiram construir os sentidos de desafio e compromisso para o trabalho com LGBT, na medida em que as profissionais acionam o discurso de despatologização. No entanto, estes desafios também são associados às situações "problema", como notamos no diálogo entre Laranja e Vermelha sobre o caso de Arco-íris:

Laranja: às vezes a gente fala "a bucha sobra sempre tudo para a gente, né”, e a gente está falando de uma situação de gênero aqui, mas assim, é tudo, não importa o que o paciente tenha, qual for a situação (Encontro 2).

Laranja relaciona a situação de gênero em questão (Caso de Arco-Íris) com as situações problemáticas e/ou de difícil resolução que a Psicologia tem que atender nos serviços de saúde.

Reunimos no Quadro 3 os sentidos construídos neste eixo e os termos e expressões associados a cada um deles.

\section{Quadro 3}

Da dificuldade ao compromisso: a constante inovação das práticas psicológicas.

\begin{tabular}{|c|c|}
\hline Sentidos & Termos que contribuíram para a construção dos sentidos \\
\hline Novidade & $\begin{array}{l}\text { Assunto que era novo; pensar junto; isso eu não conhecia; buscando respostas; ignorância no } \\
\text { sentido de que não sabe }\end{array}$ \\
\hline Delicado & $\begin{array}{l}\text { Dificuldade escolar; é delicado isso; discurso machista; não trouxe para atendimento; não } \\
\text { tem acolhimento }\end{array}$ \\
\hline Desconcertante & Limitação; era surra mesmo; não traz para atendimento; foi frustrante \\
\hline Difícil, desafio & $\begin{array}{l}\text { Limitação com relação ao assunto; corrigir o menino; lançar mais um desafio; difícil pensar } \\
\text { dessa maneira }\end{array}$ \\
\hline Compromisso & $\begin{array}{l}\text { Buscar mais informação; então procurei; pensar junto para auxiliar; continuação de } \\
\text { discussões; discurso preconceituoso; irresponsabilidade; acolhimento; não é transtorno; } \\
\text { cuidadosa; politizado }\end{array}$ \\
\hline Problema & $\begin{array}{l}\text { Era surra mesmo; queria Ritalina; não querer se envolver; fechar os olhos; depois dele tem } \\
\text { outro; bucha sempre para a gente; não adianta, é seu compromisso }\end{array}$ \\
\hline
\end{tabular}




\section{Discussão}

\section{Analisando os sentidos a partir dos diálogos produzidos nas oficinas}

A análise dos sentidos construídos na oficina permite-nos dizer que as práticas das profissionais são caracterizadas pela polivocalidade (multiplicidade de vozes) e pela polifonia (diversidade de sentidos) sobre diversidade sexual. Essa multiplicidade reflete o movimento de deslocamento discursivo da Psicologia com relação a produção de entendimentos sobre a diversidade sexual ao longo de sua história, tal como destacado na introdução deste trabalho. A consideração dessa multiplicidade de vozes e discursos pode nos ajudar a entender o desconhecimento sobre a diversidade sexual ao qual as profissionais fazem referência ao longo da oficina. Ou seja, pode-se tratar mais de uma dificuldade em se localizar seguramente no meio de discursos variados do que de um desconhecimento de algo sobre o qual a Psicologia, praticamente desde seu princípio enquanto ciência, tem se dedicado.

Pensar o desconhecido como enigma, nos remete a uma relação complexa com regimes de inteligibilidade, ou seja, com aquilo que pode ou não pode ser reconhecido e compreendido, e a função que esse saber, ou sua ausência, tem em sua regulação social (Foucault 1987/2015). O inteligível aqui pode ser entendido como aquilo que está de acordo com a matriz de compreensão cultural dominante, no caso a matriz binária de inteligibilidade de gênero (Butler, 1990/2003) e a linearidade do sistema sexo/gênero (Rubin, 1975). Aquilo que escapa desse marco será tomado como ininteligível.

Gayle Rubin explica o sistema sexo/gênero como um sistema cultural que estabelece um padrão binário em que a pessoa que nasce reconhecida como fêmea - com vulva e útero -, deve ser feminina e seus traços "masculinos" devem ser reprimidos. Os homens, por sua vez, ao nascerem reconhecidos como machos - com pênis e testículos -, devem ser masculinos e reprimir "qualquer versão de traços 'femininos"” (1975, p. 28). Esse sistema também impõe o desejo de forma específica: "gênero não é apenas uma identificação com um sexo; ele obriga também a que o desejo sexual seja orientado para o outro sexo" (1975, p. 28), ou seja, heterossexual. Esta obrigatoriedade é característica do que Adrienne Rich denomina como heterossexualidade compulsória.
O termo "heterossexualidade compulsória" designa a obrigatoriedade social de as pessoas se relacionarem amorosa e sexualmente com pessoas do gênero oposto (Rich, 2012). A obrigatoriedade é entendida a partir da não apresentação das outras vivências como possibilidades e a desvalorização do não heterossexual de modo a fazer da heterossexualidade a única possibilidade legítima. Ao termos no convívio social apenas a heterossexualidade como possível, pouco ou nada se fala sobre outras vivências sexuais e identidades de gênero, produzindo o que as participantes nomearam como tabu, aquilo que é um enigma.

Um dos efeitos de se entender algo como enigma, é a produção de um distanciamento, uma falta de identificação, que pode repercutir na falta de empatia para com a população no cuidado em saúde (Moscheta, 2011). Além disso, produz-se um efeito reverso que pode conceber a heterossexualidade como algo simples, conhecido, auto evidente e transparente, uma sexualidade sobre a qual as psicólogas sabem e não têm dificuldade de trabalhar.

Trata-se de um efeito circular da norma que coopera com a própria normalização e perpetuação em formas de sexualidade hegemônica. Nesse processo, produz-se tanto a heterossexualidade simples, quanto seu desvio, na forma misteriosa e complexa. Este processo e seu consequente distanciamento ressoa os resultados apresentados no estudo de Díaz (2012), ao apontar a falta de capacitação de profissionais de Psicologia nas UBS em Florianópolis/SC, produzindo atendimentos voltados para a família heterossexual.

O desconhecimento sobre a diversidade sexual, ao qual as profissionais fazem referência, nos permite também questionar de que modo essas possibilidades de arranjo da sexualidade foram abordadas ao longo de suas formações profissionais, como já questionado em outras pesquisas (Barreto, 2016). Destacamos aqui, em consonância com a pesquisa de Daniele Barreto (2016), a permanência de modelos de ensino e treinamento profissional em Psicologia que não assimilaram os aportes mais contemporâneos dos movimentos feministas e dos estudos de gênero, bem como o modo desta ignorância incidir na produção de práticas profissionais cujos efeitos cooperam para a regulação normativa do gênero e da sexualidade.

Quando as profissionais acionam uma noção de identidade, referindo-se a algo interno ao indivíduo, como se fosse uma estrutura identitária pronta/ 
acabada, percebemos uma naturalização da homossexualidade. A naturalização, enquanto um discurso essencialista, inclui o risco de associar a homossexualidade a um jeito de ser específico que as participantes destacam como normal. Contudo, esse 'homossexual normal' deve justamente estar de acordo com as normas sociais que regulam a expressão de sua sexualidade. No discurso das participantes, o homossexual normal é equacionado àqueles que mantém sua sexualidade relativamente disfarçada, em oposição aqueles que incomodam por serem demasiadamente extravagantes. Por isso, a visibilidade incomoda. $\mathrm{O}$ incômodo se faz presente em diferentes contextos, na rua, nas UBS, na universidade, dentro de casa, sempre que a sexualidade aparecer publicamente (Díaz, 2012; Nardi et al., 2013).

Como pano de fundo desses recortes, apontamos a noção essencialista e biologista que constitui uma visão tradicional e normativa da Psicologia. É com essa naturalização e com a heterossexualidade compulsória (Rich, 2012) que a homossexualidade e identidade transgênero são deslegitimadas enquanto possibilidades, são consideradas como uma "fase" de descobertas, de curiosidade.

O naturalizar só pode existir se produzir a noção de anormais. Assim como as noções de "falha", "desvio", "disfunção" e "anomalia de comportamento", presentes nas falas de psicólogas e psicólogos clínicos das pesquisas de Detoni et al. (2011) e da pesquisa de Moita (2006), ainda que as e os profissionais não se reconheçam como preconceituosas/os (Bessa, 2014; Moita, 2006; Rios \& Nascimento, 2007).

Identificamos tanto discursos de militância quanto acadêmico-científicos introduzidos nos discursos das profissionais, formadas em diferentes tempos. Todavia, ao acionarem discursos de militância, notamos uma apropriação de modo particular, muitas vezes, sem revolucionar alguns antigos entendimentos e, por vezes, "costurando-os".

A lógica heterossexista rege os entendimentos hegemônicos das ciências, rege as teorias psicológicas mais conhecidas e impregna a grade curricular dos cursos com a noção de um ser humano padrão, com estruturas razoavelmente estáveis de personalidade. A Psicologia tradicional estuda a diversidade como desvio reafirmando a norma a serviço da heterossexualidade compulsória.

Para além desta lógica, temos percepções de profissionais de saúde sobre a população LGBT aprisiona- das em tristeza, sofrimento, opressão e violência, conforme já descrito em outro estudo (Moscheta, 2011). Nesta pesquisa, percebemos a associação de pessoas LGBT a uma condição de sofrimento, como quando acionam os repertórios "sofrimento", "bullying" $e$ "futuro menos promissor".

No entanto, sofrimento e vulnerabilidade não são o único - nem o principal - cenário dos nossos dias. Temos acompanhado construções de redes sociais, redes de apoio, vínculos profissionais, amorosos e de amizade que configuram possibilidades de descrição da vida de pessoas LGBT para além desses termos sombrios.

A Psicologia reitera a norma quando estabelece padrões de desenvolvimento sexual de meninas e de meninos, quando cria e compartilha teorias explicativas sobre o psiquismo feminino e masculino, produzindo e reiterando, consequentemente, o desvio. É essa norma que engendra relações conflitantes e o fracasso no acolhimento da e do diferente e seus efeitos, dentre eles, o sofrimento.

As construções na oficina nos permitem analisar uma hierarquização entre hétero e homo, em que a homossexualidade é inferior e indesejada e a heterossexualidade é valorizada e almejada. Percebemos entendimentos da diversidade sexual como um problema e como algo ruim de se trabalhar. Estas noções podem produzir intervenções psicológicas com o intuito de 'reverter' ou 'evitar' a homossexualidade nos atendimentos.

Notamos que muitos dos sentidos caracterizam alguns conceitos e equívocos pré-estabelecidos de forma invisível, silenciosa e corriqueira (Borrillo, 2010). As participantes, por vezes, não se percebem preconceituosas, no entanto, nos deparamos com construções linguísticas que inferiorizam a homossexualidade, patologizam a identidade trans e fragilizam, de modo geral, as sexualidades dissidentes como em momentos em que associam pessoas LGBT com Infecções Sexualmente Transmissíveis (IST), ou quando se referem à vivência dessas pessoas como uma "fase de descobertas". Isso repercute os resultados de outras pesquisas, que apontam que embora profissionais da Psicologia não se considerem preconceituosas/os, elas/es 'deslizam' em falas preconceituosas e hierarquizantes (Moita, 2006; Rios \& Nascimento, 2007; Díaz, 2012; Sposito, 2015).

De modo geral, as participantes se posicionam como defensoras de pessoas LGBT como sujeitos de 
direitos e afirmam o desejo de saber mais sobre o assunto e lutar pela garantia desses direitos.

Os relatos de atendimentos contemplam o entendimento da transgeneridade como um enigma. Na oficina, as pessoas trans são descritas como seres ininteligíveis. Ao mesmo tempo, notamos uma postura de "não saber" que faz o possível para ser respeitosa e garantir o direito de atendimento e o acolhimento adequado àquela identidade ininteligível. Esse entendimento coincide com as reinvenções da Psicologia, que pretendem trabalhar alinhadas ao contexto social e seus efeitos, e não com uma individualidade abstrata e isolada (Detoni et al., 2011), como podemos perceber a partir dos documentos e resoluções já citados.

Por isso é tão importante a proposta de formação continuada no SUS. Os encontros reflexivos e informativos sobre o assunto têm a potência de contribuir para ressignificar essas noções hieraquizantes e patologizantes e qualificar a assistência à saúde da população LGBT (Brasil, 2003, 2013).

Essas reflexões têm como pano de fundo algumas discussões contemporâneas no cenário da Psicologia, principalmente, as discussões com base foucaultiana, que contemplam processos de subjetivação, questionamentos das normas sociais que compõem nossas relações e os marcadores sociais da diferença (raça/etnia, gênero, sexo, idade, classe social e sexualidade), bem como a atenção para a presença de machismo, racismo, misoginia e lgbtfobia nas teorias e práticas psicológicas (Peres, 2013).

Outro movimento de valorização da diversidade foi a associação entre pessoas LGBT e afeto. As participantes se referiram à população LGBT como pessoas afetuosasas, considerando o amor e o afeto como algo presente nas relações tanto hétero, quanto homo. Ao fazer isso, elas equalizam as relações hétero e homo em um modelo que valoriza o afeto e o amor, sem hierarquizá-las. Ao mesmo tempo, ao equalizá-las, elas aproximam as relações homo do normativo, ou seja, dos casamentos heterossexuais monogâmicos. Isso também engendra normatização (heteronormatividade).

Ao longo da oficina, deparamo-nos com o acionamento de saberes e discursos patologizantes, hierarquizantes e depreciativos, mesclados com falas apreciativas e implicadas ética e politicamente com a garantia de direitos. As concepções contemporâneas dialogam com o atual posicionamento do Conselho
Federal de Psicologia, anunciado publicamente por meio das resoluções citadas anteriormente.

As participantes recorrem a diferentes conhecimentos para produzir entendimento sobre a temática e constroem múltiplos sentidos, configurando a polivocalidade e a polifonia que temos hoje no campo. Acessando e acionando diferentes saberes, colocam-se abertas à reflexão e questionamentos.

Entendemos que é este posicionamento que leva as participantes a acionarem a rede, buscarem o máximo de informações possível sobre a pessoa, com a família, com a escola e com outros serviços. A busca de informações, para além da Rede de Atenção à Saúde (RAS) - como elas relatam que fizeram para atender Arco-íris, pode estar relacionada ao sentido de enigma, é como o movimento de buscar auxílio para desvendá-lo. Há uma procura pelo caminho da despatologização, que, por menos conhecido que seja, 'parece-lhes' mais coerente com os princípios do SUS (Brasil, 1990; Souza et al., 2013).

Ao se mobilizarem e recusarem a possibilidade de correção de comportamentos dissidentes sexuais e de gênero, analisamos que as profissionais atuam alinhadas às propostas do Conselho Federal de Psicologia. Consideramos essa postura como efeito da Resolução no 001/1999 (Resolução CFP n. $1,1999)$ e das discussões que a circunscrevem. Isto é, identificamos discursos militantes e seus efeitos, e também discursos da categoria profissional inseridos no cotidiano das psicólogas, aos quais elas se mostram sensíveis. Esses efeitos reiteram a importância da Resolução, que tem sua vigência ameaçada constantemente.

Com relação às dificuldades, as participantes relatam especificamente duas: a) sobre conceitos; $\mathrm{e}$ b) com relação aos serviços. Estas dificuldades nos permitem analisar que há um desconhecimento sobre a temática, que se configura pela ininteligibilidade (Butler, 1990/2003) -, que relacionamos aos sentidos de enigma, tabu e surpresa. A dificuldade com os serviços é percebida quando afirmam que não querem referenciar uma criança de 8 anos para o CAPS porque não querem "enquadrar ela nisso de transtorno" e quando se referem a colegas de trabalho com falas preconceituosas. Ao negarem o enquadramento de transtorno, relacionamos seus posicionamentos de cuidado ao sentido de pessoas LGBT como sujeitos de direitos, condizentes com o movimento de luta pela despatologi- 
zação e efetivação dos direitos humanos (Sposito, 2015; Resolução CFP n. 1, 1999).

Considerar o trabalho como delicado e desafiador, advém tanto da dificuldade de lidar com os conceitos que embasam as intervenções, quanto da quebra de expectativas das mães e pais com relação às filhas e filhos (sentido de surpresa); da busca por normalização (indesejado e sofrimento); e da contradição entre o que essas pessoas buscam ao procurar as psicólogas e a ética profissional das mesmas (sujeitos de direitos, sofrimento e vulnerabilidade). Estas expectativas estão relacionadas às práticas de ajustamento e normatização historicamente exercidas pela Psicologia (Macedo \& Dimenstein, 2012).

As profissionais se preocupam com a configuração da RAS, na estrutura atual - refletem sobre encaminhar ou não para a Rede e como pode ser significado este encaminhamento. Isso nos diz, também, da percepção que elas têm, de que a Rede nem sempre tem condições de receber a diversidade. Aqui falamos da polivocalidade na área da saúde, que pode contemplar, em um mesmo serviço de saúde, tanto olhares reducionistas - saúde como ausência de doença - e normativos - normal/anormal, padrão/desvio -, quanto olhares generalistas, ampliados e plurais saúde como processo multideterminado, relacionado ao social, valorização das diferenças e promoção de saúde, considerando os DSS (Macedo \& Dimenstein, 2012; Beato \& Ferreira, 2016).

Todavia, mesmo pensando nos direitos deste grupo populacional e no compromisso da Psicologia, como é característico da polifonia e polivocalidade, nós temos outros sentidos para o trabalho com LGBT, como o sentido de problema. Esse sentido pode ser decorrente, também, dos sentidos para a diversidade sexual como indesejado, condição individual, surpresa e visibilidade que incomoda.

Acolhendo as demandas como problema ou como desafio, o trabalho é caracterizado como difícil e delicado. Isso porque não conhecem a temática, então é vista como um problema muito grande, porque desafia os regimes de manutenção de gênero hegemônicos. Também dificulta a escassez de recursos para a formação sobre a política de saúde LGBT e conhecimentos que supram a deficiências da formação. O olhar sobre os Determinantes Sociais de Saúde requer delicadeza e complexifica o trabalho. Questionar as normas sociais dentro de espaços institucionais é sempre um desafio, torna o trabalho mais complexo e exige habilidades relacionais e engajamento ético político, para além da competência técnica.

As profissionais lidam, cotidianamente, com a novidade, uma vez que as pessoas são diferentes, com vivências diferentes e necessidades de saúde específicas. E é esse constante rearranjo da conjuntura social que exige formação continuada e educação permanente (Brasil, 2003).

\section{Considerações finais}

Todo este cenário nos permite apontar a permeabilidade da Psicologia, uma ciência múltipla e em constante transformação. Uma ciência que, apesar de ter vigentes os discursos médico-patologizante e o psicologismo especialista, é permeável também àquilo que emerge em outros campos de conhecimento como os estudos em gênero e sexualidade, sobretudo de matriz feminista, que tensionam e ampliam seu arcabouço teórico. Mas é permeável também ao que emerge dos movimentos sociais, sobretudo os de militância LGBT, nos quais muitas psicólogas e psicólogos tem atuado. $\mathrm{O}$ acionamento dos discursos de luta por direitos, evidencia que o que temos construído em termos de práticas de militância, têm reverberado em mudanças dentro da ciência, das práticas psicológicas e do sistema de saúde brasileiro, ainda que paulatinamente.

Todavia, é importante reafirmar a peculiaridade do grupo participante, uma vez que nós dialogamos com as doze primeiras psicólogas que se inscreveram para a oficina. Elas já faziam algumas discussões acerca da temática nas equipes e haviam procurado materiais a respeito antes de participarem da oficina. Isso configura o interesse e abertura das profissionais para falar sobre o assunto e não pode ser tomado como uma representação mais geral do campo profissional.

Ademais, na contramão da universalização dos conhecimentos científicos, procuramos, com a pesquisa, analisar um contexto específico, dialogando com outros contextos, de outras pesquisas, e apontar a importância de todas as formas de resistências possíveis, dentro e fora da academia. Dentre estas possibilidades, destacamos a qualificação da atenção à saúde da população LGBT, por meio de capacitações sobre a temática, como já prevê a Política Nacional de Atenção Integral à Saúde da População LGBT (Brasil, 2013). 


\section{Referências}

American Psychiatry Association - APA. (2014). DSM-5: Manual diagnóstico e estatístico de transtornos mentais. Porto Alegre, RS: Artmed.

Barreto, D. J. (2016). A (in)visibilidade dos prazeres, das sexualidades e dos gêneros e a parresia na formação queerizada em psicologia: Narrativas de outras perspectivas e experiências docentes (Tese doutorado). Faculdade de Ciências e Letras, Universidade Estadual Paulista, Assis, SP, Brasil.

Beato, M. S. F., \& Ferreira, J. L., Neto. (2016). Formação em psicologia em uma universidade pública e suas repercussões nas competências do trabalho em políticas públicas. Psicologia em Revista, 22(2), 514-534. https://doi. org/10.5752/P.1678-9523.2016V22N2P516

Bessa, G. (2014). Sentidos de psicoterapia para homens gays (Dissertação de mestrado). Instituto de Psicologia, Universidade Federal de Uberlândia, Uberlândia, MG, Brasil.

Borges, L. S. (2014). Feminismos, teoria queer e psicologia social crítica: (Re)contando histórias... Psicologia \& Sociedade, 26(2), 280-289. https://doi.org/10.1590/S0102-71822014000200005

Borrillo, D. (2010). Homofobia: História e crítica de um preconceito. Belo Horizonte, MG: Autêntica.

Brasil. Ministério da Saúde. (1990). ABC do SUS: Doutrinas e princípios. Brasília, DF: Secretaria Nacional de Assistência à Saúde.

Brasil. Ministério da Saúde. (2003). Políticas de formação e desenvolvimento para o SUS: Caminhos para educação permanente em saúde. Brasília, DF: o autor. Recuperado de http://bvsms.saude.gov.br/bvs/publicacoes/pol_formacao_desenv.pdf

Brasil. Ministério da Saúde. (2012). Política nacional de atenção básica. Brasília, DF: Secretaria de Atenção à Saúde.

Brasil. Ministério da Saúde. (2013). Política nacional de saúde integral de lésbicas, gays, bissexuais, travestis e transexuais (2a ed.). Brasília, DF: o autor.

Butler, J. (2003). Problemas de gênero: Feminismo e subversão da identidade (R. Aguiar, Trad.). Rio de Janeiro, RJ: Civilização brasileira. (Obra original publicada em 1990).

Conselho Federal de Psicologia - CFP. (2013). Nota técnica sobre processo transexualizador e demais formas de assistência às pessoas trans. Brasília, DF: o autor.

Constituição da República Federativa do Brasil: Promulgada em 5 de outubro de 1988. (1988). Brasília, DF: Senado Federal.

Detoni, P. P., Marques, D. M., Soares, L. V., \& Nardi, H. C. (2011). As formas do "fazer psi” e a constituição das políticas públicas associadas à diversidade sexual. Revista Psicología Política, 11(22), 279-294.

Díaz, G. A. (2012). Sexualidade(s): Concepções de psicólogos/as de unidades básicas de saúde de Florianópolis (Dissertação de mestrado). Centro de Filosofia e Ciências Humanas, Universidade Federal de Santa Catarina, Florianópolis, SC, Brasil.

Dinis, N. F. (2012). Discursos sobre homossexualidade e gênero em um curso de formação em psicologia. Educação Temática Digital, 14(1), 62-75. https://doi.org/10.20396/etd.v14il.1241

Foucault, M. (2015). A história da sexualidade 1: A vontade de saber (M. T. C. Albuquerque, \& J. A. G. Albuquerque, Trads., 2a ed.). São Paulo, SP: Paz e Terra. (Obra original publicada em 1987).

Gimenes, A. P., \& Vieira, T. R. (2012). Homoafetividade: De sodoma ao STF. In T. R. Vieira (Org.), Minorias sexuais: Direitos e preconceitos (pp. 141-164). Brasília, DF: Consulex.

Guanaes, C., \& Japur, M. (2008). Contribuições da poética social à pesquisa em psicoterapia de grupo. Estudos de Psicologia (Natal), 13(2), 117-124. https://doi.org/10.1590/S1413-294X2008000200003

Lei n. 8.080, de 19 de setembro de 1990. Dispõe sobre as condições para a promoção, proteção e recuperação da saúde, a organização e o funcionamento dos serviços correspondentes e dá outras providências. Diário Oficial da União.

Louro, G. L. (2008). Gênero e sexualidade: Pedagogias contemporâneas. Pro-Posições, 19(2), 17-23. https:// doi.org/10.1590/S0103-73072008000200003

Macedo, J. P., \& Dimenstein, M. (2012). Modos de inserção dos psicólogos na saúde mental e suas implicações no comprometimento com a reforma psiquiátrica? Revista Mal-Estar e Subjetividade, 12(1/2), 419-456. 
Moita, G. (2006). A patologização da diversidade sexual: Homofobia no discurso de clínicos. Revista Crítica de Ciências Sociais, (76), 53-72.

Moscheta, M. S. (2011). Responsividade como recurso relacional para a qualificação da assistência à saúde de lésbicas, gays, bissexuais, travestir e transexuais (Tese de doutorado). Faculdade de Filosofia, Ciências e Letras de Ribeirão Preto, Universidade de São Paulo, Ribeirão Preto, SP, Brasil.

Nardi, H. C., Machado, P. S., Machado, F. V., \& Zenevich, L. (2013). O “armário" da universidade: O silêncio institucional e a violência, entre a espetacularização e a vivência cotidiana dos preconceitos sexuais e de gênero. Teoria \& Sociedade, 2(21), 179-200.

Organização Mundial da Saúde - OMS. (1998). CID-10 classificação estatística internacional de doenças e problemas relacionados à saúde (versão 1.6c). Brasília, DF: Datasus. Recuperado de http://www.cremesp.org.br/pdfs/ cid10_ultimaversaodisponivel_2012.pdf

Organização Mundial da Saúde - OMS. (2018). OMS divulga nova CID-11. Brasília, DF: OPAS-Brasil. Recuperado de https://www.psiquiatriaocupacional.com.br/Blog/cid-11

Peres, W. S. (2013). Psicologia e políticas queer. In F. S. Teixeira Filho (Ed.), Queering: Problematizações e insurgências na psicologia contemporânea (pp. 55-64). Cuiabá, MT: Universidade Federal do Mato Grosso.

Portaria n. 2.436, de 21 de setembro de 2017. Aprova a política nacional de atenção Básica, estabelecendo a revisão de diretrizes para a organização da atenção básica, no âmbito do Sistema Único de Saúde (SUS). Diário Oficial da União. Recuperado de http://bvsms.saude.gov.br/bvs/saudelegis/gm/2017/prt2436_22_09_2017.html

Resolução CFP n. 1, de 22 de março de 1999. Estabelece normas de atuação para os psicólogos em relação à questão da orientação sexual. Diário Oficial da União. Recuperado de https://site.cfp.org.br/wp-content/uploads/1999/03/resolucao1999_1.pdf

Resolução CFP n. 1, de 29 de janeiro de 2018. Estabelece normas de atuação para as psicólogas e os psicólogos em relação às pessoas transexuais e travestis. Diário Oficial da União. Recuperado de http://site.cfp.org.br/wp-content/uploads/2018/01/Resolu\%C3\%A7\%C3\%A3o-CFP-01-2018.pdf

Rich, A. (2012). Heterossexualidade compulsória e existência lésbica (C. G. Valle, Trad.). Bágoas, 4(5), 17-44.

Rios, L. F., \& Nascimento, I. F. (2007). Homossexualidade e terapia infantil: Possibilidades e desafios para a construção dos direitos sexuais na clínica psicológica. Revista Psicologia Política, 7(13).

Rubin, G. (1975). O tráfico de mulheres: Notas sobre a "economia política" do sexo. Recife, PE: SOS Corpo. Recuperado de https://edisciplinas.usp.br/pluginfile.php/1740519/mod_resource/content/1/Gayle\%20Rubin_trafico_texto\%20traduzido\%20\%286\%29.pdf

Souza, D. O., Silva, S. E. V., \& Silva, N. O. (2013). Determinantes sociais da saúde: Reflexões a partir das raízes da “questão social”. Saúde e Sociedade, 22(1), 44-56. https://doi.org/10.1590/S0104-12902013000100006

Spink, M. J., \& Medrado, B. (2013) Produção de sentidos no cotidiano. In M. J. Spink (Org.), Práticas discursivas e produção de sentidos no cotidiano: Aproximações teóricas e metodológicas. Rio de Janeiro, RJ: Centro Edelstein de Pesquisas Sociais.

Spink, M. J. (2010). Linguagem e produção de sentidos no cotidiano. Rio de Janeiro, RJ: Centro Edelstein de Pesquisas Sociais.

Spink, M. J., Menegon, V. M., \& Medrado, B. (2014). Oficinas como estratégia de pesquisa: Articulações teórico-metodológicas e aplicações ético-políticas. Psicologia \& Sociedade, 26(1), 32-43.https://doi.org/10.1590/S0102-71822014000100005

Sposito, S. E. (2015). Homossexualidades nas pesquisas em pós-graduação em psicologia: Da despatologizaçãoà luta por direitos (Tese de doutorado). Faculdade de Ciências e Letras de Assis, Universidade Estadual Paulista, Assis, SP, Brasil.

Teixeira, F. S., Filho. (2011a). Apontamentos para uma psicologia contra-homófobica. In Conselho Federal de Psicologia - CFP (Org), Psicologia e diversidade sexual: Desafios para uma sociedade de direitos (pp. 49-66). Brasília, DF: o autor.

Teixeira, F. S., Filho. (2011b). Homofobia e sua relação com as práticas "psi". In Conselho Regional de Psicologia da 6 ${ }^{a}$ Região - CRP-6 (Org.), Psicologia e diversidade sexual (Cadernos temáticos 11, pp. 33-40). São Paulo, SP: o autor.

Toneli, M. J. F. (2008). Diversidade sexual humana: Notas para a discussão no âmbito da psicologia e dos direitos humanos. Psicologia Clínica, 20(2), 61-73. https:// doi.org/10.1590/S0103-56652008000200005

Vecchiatti, P. R. I. (2012). Minorias sexuais e ações afirmativas. In T. R. Vieira (Org.), Minorias sexuais: Direitos e preconceitos (pp. 29-54). Brasília, DF: Consulex. 


\section{Bárbara Anzolin}

Docente no curso de Psicologia da Universidade Paranaense (UNIPAR), Umuarama - PR. Brasil. Mestra em Psicologia pela Universidade Estadual de Maringá (UEM), Maringá - PR. Brasil.

E-mail: bah.anzolin@gmail.com

Essa pesquisa foi desenvolvida com apoio financeiro da Coordenação de Aperfeiçoamento de Pessoal de Nível Superior (iD https:// orcid.org/0000-0002-4301-7828

Murilo dos Santos Moscheta

Docente do Programa de Pós-graduação em Psicologia da Universidade Estadual de Maringá (UEM), Maringá-PR. Brasil. E-mail: murilomoscheta@me.com

(iD) https://orcid.org/0000-0001-7479-2651

Endereço para envio de correspondência:

Rua minas gerais, 2195, apto 92. Cascavel-PR. CEP 85812-030

Recebido 12/09/2019

Aceito 04/10/2019

Received 09/12/2019

Approved 10/04/2019

Recibido 12/09/2019

Aceptado 04/10/2019

Como citar: Anzolin, B., \& Moscheta, M.S. (2019). Sentidos sobre Diversidade Sexual e o Trabalho de Psicólogas na Atenção Básica. Psicologia: Ciência e Profissão, 39 (n.spe 3), 1-16. https://doi.org/10.1590/1982-3703003228644

How to cite: Anzolin, B., \& Moscheta, M.S. (2019). Meanings about Sexual Diversity and Professional Practices of Psychologist in Primary Care. Psicologia: Ciência e Profissão, 39 (n.spe 3), 1-16.

https://doi.org/10.1590/1982-3703003228644

Cómo citar: Anzolin, B., \& Moscheta, M.S. (2019). Sentidos sobre la Diversidad Sexual y el Trabajo de Psicólogas en la Atención Básica. Psicologia: Ciência e Profissão, 39 (n.spe 3), 1-16. https://doi.org/10.1590/1982-3703003228644 